\title{
Resenha: Revisando a Prática de Publicar: Para Profissionais e Estudantes de Psicologia.
}

\author{
Deolinda Armani Turci ${ }^{1}$ \\ Faculdade de Educação-Universidade Federal de Minas Gerais.
}

\author{
Book Review: Revising the Practical one to Publish: \\ For Professionals and Students of Psychology.
}

Publicar textos científicos é uma grande preocupação de vários profissionais, principalmente para aqueles que se iniciam nesta prática. As dúvidas acontecem desde a estrutura do artigo até a decisão de onde publicar a produção.

$\mathrm{Na}$ área da Psicologia, as preocupações também acometem os alunos e os profissionais que se dispõem a publicar algo. Se compararmos o número de psicólogos que anualmente entram no mercado de trabalho, podemos perceber que poucos enveredam pelo árduo caminho da pesquisa científica ou mesmo se dispõem a publicar suas produções. Outro agravante é a preparação do estudante ou do profissional para que os mesmos produzam trabalhos que sejam tão logo aprovados para publicações em periódicos da área psicológica.

O livro Publicar em Psicologia, organizado por Apareceida Zoqui P. Sabadini, Maria Imaculada C. Sampaio e Sílvia Helena Koller (2009), é uma obra que pode preencher esta lacuna em publicações de trabalhos científicos, principalmente em revistas científicas, que é o enfoque do mesmo. Destina-se a estudantes e ou profissionais interessados em conhecer o processo de gerenciamento de publicações e da editoração científica na área da Psicologia ou nas diversas áreas do conhecimento.

Está dividido em nove (9) capítulos, produzidos por nove (9) autores graduados, pós-graduados e experientes em publicações diversas em Psicologia e áreas afins. Baseado nas Normais Técnicas da Associação Brasileira de Normas Técnicas (ABNT) e nos manuais da American Psychological Association (APA). O livro é uma coletânea de orientações práticas para profissionais que desejam publicar textos científicos em periódicos e ou ampliar discussões sobre a política científica nacional. Conta ainda com excelentes discussões e informações sobre propriedade intelectual e Open Access (acesso livre), indispensável aos profissionais da atualidade que formam hoje as redes de comunicação da internet.

A obra é de excelente qualidade na apresentação de informações detalhadas, precisas e pertinentes acerca das normas de publicações na maioria das revistas científicas brasileiras em Psicologia, além de apresentar um modelo inovador no que tange ao acesso livre ao conhecimento, pois antes mesmo de seu lançamento oficial, já estava disponível no site da BVS-PSI (Biblioteca Virtual em Saúde- Psicologia) para pesquisas on-line. A evolução tecnológica, a informatização de dados e o crescente número de publicações na internet

1 Endereço para Correspondência: AV, Antonio Carlos, 6.627 - Sala n. 1671- Pampulha, Belo Horizonte -MG. CEP 31270-910 E-mail: deoarmani@hotmail.com disponibilizam muito mais informação, com rapidez e agilidade, permitindo que um contingente maior de pessoas possa usufruir dessas, ampliando pesquisas e conhecimentos.

O primeiro capítulo, escrito por Piotr Trzesniak e Sílvia Koller, editores experientes, trata do tema da redação científica e de suas peculiaridades. Avaliam o caminho de um texto até sua publicação, bem como os cuidados dos autores antes do encaminhamento de suas produções às revistas especializadas. Cuidadosamente os autores apresentam, ao final do mesmo, informações sobre o processo editorial para o aceite de um trabalho a ser publicado, visando à redução de erros e consequente publicação em menor prazo.

"Preparando um periódico científico" é o título do capitulo 2 dessa obra. As autoras Aparecida Sabadini, Maria Imaculada Sampaio e Maria Marta Nascimento nos fornecem informações e orientações quanto à elaboração e padronização de periódicos científicos, para que os mesmos sejam aceitos e mantidos no meio acadêmico. Todas as características peculiares a um periódico científico são expostas pelas autoras. Minuciosamente cuidou-se de apresentar dados que às vezes nos são imperceptíveis ao submetermos nossos textos à publicação. A estrutura do periódico é apresentada em seus elementos pré-textuais, textuais e pós-textuais, além de pontos relevantes que os editores devem cuidar, ao prepararem um periódico científico, impresso e/ou digital. Ao final do capítulo apresentam anexos contendo modelos de todos os itens de estrutura dos periódicos científicos que facilitam bastante a visualização dos mesmos.

No capítulo 3, Maria Imaculada Sampaio e André Serradas discutem o impacto das Tecnologias de Informação e Comunicação (TIC) na vida atual, onde a internet é um instrumento de conhecimento compartilhado e o movimento de acesso aberto amplia a visão do leitor quanto à disponibilização e distribuição da informação científica para consultas acadêmicas. Os repositores institucionais e temáticos, onde o uso dos softwares livres se torna vantajoso aos usuários e desenvolvedores deste sistema, também é tema deste capítulo. É indicado ainda pelos autores o site Scielo (Scientific Eletronic Library On line) como uma iniciativa das mais profícuas de acesso livre na internet, além de ser um site seguro e de qualidade para pesquisas científicas.

O texto de Piotr Trzesniak, capítulo 4, tem como tema a estrutura editorial de periódicos científicos no qual o autor expõe, desde a importância da existência de retaguarda insitucional e do Comitê ou Conselho de Política Editorial para assegurar a continuidade da publicação do periódico, até a garantia de credibilidade científica dada pelo Corpo Editorial 
científico, pelos consultores, revisores ou pareceristas e pela Editora, não só na publicação do periódico, como também divulgação, leitura e citação dos artigos publicados pela mesma.

Ao lermos o capítulo 5, de Sampaio e Sabadini, com o título "Indexação e Fatos de Impacto" poderemos pesquisar e nos informarmos sobre a indexação, largamente empregado entre editores e pesquisadores. As autoras conceituam o termo e apresentam os critérios usados na avaliação e inclusão de um periódico a uma base de dados, além disto, fornecem os procedimentos para indexação de periódicos. Neste capítulo podemos perceber também como a internet foi vantajosa e benéfica aos usuários de bases de dados, pois a informatização aumentou a precisão e a rapidez no acesso às informações das mesmas.

Peculiaridades sobre um artigo científico, ás vezes, nos passam despercebidos. No capítulo 6, Sabadini, Sampaio e Sílvia Kelly orientam o leitor sobre como preparar um artigo. Expõem a estrutura e o conteúdo que devem compor o mesmo, bem como as sutilezas no percurso para publicação mais rápida do texto. Com base no manual da APA, as autoras disponibilizam informações práticas e úteis acerca de um artigo científico. O detalhamento de tópicos possibilita ao leitor aventurar-se na escrita de um texto científico, tendo como referência os dados práticos compilados pelas autoras.

O Título do capítulo 7 é "Autoria, Coautoria e Colaboração". Neste, as autoras Sampaio e Sabadini tratam dos vários e polêmicos conceitos sobre as questões pertinentes ao tema. Discutem o comprometimento e a ética necessária aos mesmos e enriquecem as discussões que se agravam na atualidade. É indiscutível o investimento intelectual feito pelos pares nas diversas modalidades de pesquisa e publicações científicas, e cada um em sua função agrega certificação e reconhecimento para os envolvidos. É necessário que se conheça o conceito de cada uma das atuações para possíveis discussões. Segundo as autoras e de modo geral, o primeiro nome em um trabalho científico é do autor responsável pela maior parte do trabalho, formatação, revisão e envio. Posteriormente vêm os nomes dos coautores e colaboradores, que estariam envolvidos e atrelados a cooperação e análise, dentre outros fatores que envolvem o trabalho. A discussão é ampla e está longe do consenso, é imprescindível, antes de tudo, que a ética e o bom senso prevaleçam.

No capítulo 8, Vendramini, Cazorla e Silva vão nos apresentar as normas de publicação científica de informações que envolvem tabelas e figuras estatísticas, bem como notações e expressões baseadas nas normas da APA, nos orientando e fazendo algumas comparações com as normas e sistemas adotados no Brasil. Informações como as sugeridas neste capítulo, são bastante pertinentes já que não são encontradas em qualquer manual, principalmente no que tange a escrita de notações e expressões estatísticas. Como na maioria das vezes, as pesquisas envolvem estatísticas que podem ser disponibilizadas em gráficos, tabelas e em apresentações de resultados, termos acesso a forma mais precisa de fazê-los, é indispensável ao pesquisador e aqui neste capítulo podemos ter acesso, com bastante detalhamento, a diversos exemplos referentes a análise exploratória de dados e a apresentação correta de medidas estatísticas.

Yamamoto e Costa finalizam o livro no capítulo 9, avaliando os periódicos científicos brasileiros na área da Psicologia, após a proliferação de títulos que se espalham nesta atualidade e remetem-nos a uma reflexão sobre os mesmos. Quando empreendemos na árdua tarefa de fazermos pesquisas e artigos, nada mais justo que envolvermos também na análise e escolha de onde faremos a publicação de nossos trabalhos. Nesse capítulo, os autores nos orientam sobre a importância de buscarmos o padrão de qualidade e a indexação dos mesmos, bem como a avaliação dos periódicos pela CAPES (Coordenação de Aperfeiçoamento de Pessoal de Nível Superior) / ANPEPP (Associação Nacional de Pesquisa e Pós-graduação em Psicologia).

Os autores do livro foram felizes e de bom gosto na escolha dos temas, reunindo informações polêmicas e pertinentes num único manual. Com conteúdos atuais e importantes para a elaboração e publicação de textos científicos, os temas abordados por eles, muitas vezes, são esquecidos e desconhecidos entre alunos da graduação e futuros profissionais da Psicologia.

O livro representa excelente contribuição a alunos e profissionais que desejam publicar artigos em periódicos de qualidade da área da Psicologia e para os que participam de discussões a cerca da política científica nacional. Atende também ao público que se inicia em discussões pertinentes ao acesso livre de informações e à propriedade intelectual na internet, sendo inclusive um norteador desses temas para os vários educadores e pesquisadores que ainda se assustam com as possibilidades da internet.

Atualmente é importe contarmos com obras, como esta, que trata de temas indispensáveis e atuais para a produção do conhecimento e da informação, ao mesmo tempo em que pontua discussões indispensáveis a alunos, educadores e pesquisadores das diversas áreas do conhecimento.

\section{Referência}

Sabadini, A. A. Z. P., Sampaio, M. I.C. \& Koller, S. H. (Orgs.) (2009). Publicar em Psicologia: um enfoque para a Revista Científica. São Paulo: Casa do psicólogo.

\author{
Recebido em 16.09.09 \\ Primeira decisão editorial em 12.05.10 \\ Aceito em 12.05.10
}

